\title{
Ruh Sağlığını Koruma ve İyileştirmede Hayvan Destekli Uygulamaların Kullanımı
}

\section{The Use of Animal-Assisted Practices to Protect and to Recover Mental Health}

\author{
Şeyma DEMiRALAY * \\ İlkay KESER **
}

\begin{abstract}
Öz: Ruhsal hastalıkların görülme sıklığı arttıkça, ruh sağlığını koruma ve geliştirmeye yönelik farklı tedavi yöntemleri kullanılmaktadır. Hayvan Destekli Uygulamaların kullanımı yurt dışında yaygın olmakla birlikte ülkemizde kullanılması ve çalışma sonuçlarına yansıma oranı oldukça sınırı bir tedavi yöntemidir. Bu yöntem, sağlığı geliştirmek amacıyla destek tedavisi olarak uygulanmakta, insan ve hayvan etkileşimine dayanmaktadır. $\mathrm{Bu}$ çalışmada, hayvan destekli uygulamanın etki mekanizmasını, uygulama alanlarını, ruh sağlığını koruma ve iyileştirmedeki önemini değerlendirmek amaçlanmıştır. Literatürde, hayvan besleme ya da hayvanlarla birlikte olmanın, bireyin ruhsal, fiziksel ve sosyal sağlığını koruma ve geliştirmede önemli bir katkısı olduğu ortaya konmaktadır. Uygulamanın, farklı gelişim dönemlerinde, sağlıklı ve hasta bireylerde uygulanabildiği, hem fiziksel hem de ruhsal hastalıkların tedavisinde destekleyici bir tedavi olarak kullanılabileceği belirtilmektedir. Hayvanların varlığının ve hayvanla geçirilen zamanın bireyin egzersiz yapma ve kendi bakımına katılma oranını artırdığı, kan basıncını ve dolayısıyla kardiyovasküler sistemini düzenlediği, bağımlılık düzeyini azaltarak, iletişim becerilerini olumlu yönde etkilediğine ilişkin bulgular mevcuttur. Ruh sağlı̆̆ının korunması ve iyileştirilmesinde, bireylerin yaşam kalitesinin artırılmasında hayvan destekli aktiviteler diğer tedavilere destek ek bir tedavi yöntemidir. Bu bağlamda, hayvan destekli uygulamaların koruyucu ruh sağlığı ve klinik psikiyatrik bakım uygulamalarında kullanımının yaygınlaştırılması, kullanımının farklı çalışma sonuçları ile desteklenmesi önerilmektedir.
\end{abstract}

Anahtar sözcükler: Ruh sağlı̆̆ı, Koruma, İyileştirme, Hayvan Destekli Uygulama

\begin{abstract}
As the incidence of mental illness increases, different treatment modalities are used to protect and to improve mental health. Although the use of Animal Supported Applications is widespread abroad, its use in our country and the rate of reflection in study results is limited. This method is applied as supportive treatment to improve health and is based upon human and animal interaction. In this study, the mechanism of the animalassisted applications, with the aim of evaluating its importance in mental health protection and improvement is investigated. Feeding animals or being with the animals has been shown to make an important contribution to the protection and development of the health of the individual. It is stated that the application can be applied to healthy and sick individuals in different developmental periods, such as with children, adolescents and the elderly and it can be used as a supportive treatment in the treatment of both physical and mental diseases. There is evidence that the presence of animals and the time spent with the animal increases the individual's ability to exercise and participate in their care, regulates blood pressure and thus the cardiovascular system, and positively affects communication skills by reducing the level of dependence. In this context, it is recommended that the use of animal-assisted practices in preventive mental health and clinical psychiatric care applications should be expanded, as its usefulness is supported by different study results.
\end{abstract}

Keywords: Mental Health, Protect, Recovery, Animal Assisted Practice

* MA, Akdeniz Üniversitesi, Sağlı Bilimleri Enstitüsü, Ruh Sağlığı ve Psikiyatri Hemşireliği, Antalya. bsgseyma@gmail.com, https://orcid.org/0000-0002-5177-1919

** Dr. Öğr. Üyesi, Akdeniz Üniversitesi, Hemşirelik Fakültesi, Psikiyatri Hemşireliği ABD, Antalya. ikeser@akdeniz.edu.tr, https://orcid.org/0000-0001-6595-4188 


\section{Giriş ve Amaç}

Hayvan Destekli Uygulamalar (HDU) günümüzde çeşitli gruplarda, sağlığı koruma ve geliştirmek amaciyla uygulanan tedavilere destek ek bir müdahale seçeneği ve tedaviye motivasyon artışı sağlayan bir yöntemdir (İchitani \& Cunha 2016). Dünya'da HDU'nun kullanımı yaygın olmakla birlikte, ülkemizde bu konuda yapılmıs uygulamalar sınırlıdır. Literatürde HDU'ya ilişkin pet terapi, pet psikoterapi, hayvan destekli tedavi, hayvan destekli terapi, hayvan destekli aktivite gibi farklı terimler yer almaktadır. HDU'lar, terminolojide standardizasyon oluşturmak için Hayvan Destekli Tedavi (HDT) ve Hayvan Destekli Aktiviteler (HDA) olarak ikiye ayrılmıştır. HDT, bir hayvanın belli kriterlere göre tedavi sürecine katıldığı, hedefe yönelik girişimlerdir ve bu alanda uzmanlaşmış kişiler tarafından uygulanmalıdır. HDA ise, bireyin yaşam kalitesini artıran, eğitici, eğlendirici ve motivasyonu artıran aktivitelerden oluşan, özel eğitimli profesyoneller, hekim, hemşire, psikolog gibi sağlık profesyonelleri, veterinerler ve/veya gönüllüler tarafindan uygulanır. Tedavi hedeflerinin belli olmaması ve gönüllülük esasına dayanması temel özellikleridir (Kruger \& Serpell 2010). Bu derleme çalışmasında, hayvan destekli uygulamanın dayandığı teoriler, etki mekanizması ve uygulama alanları gözden geçirilerek, ruh sağlığını koruma ve iyileştirmedeki önemine dikkat çekmek amaçlanmıştır.

\section{Hayvan Destekli Uygulamaların Dayandığı Teoriler}

HDU'nun etkisi biyofili hipotezi, öğrenme teorisi, psikoanalitik teori, yeşil terapi, bağlanma, bilişsel ve sosyal kuramlar ve farklı hipotez/teorilerle açıklanmaktadır. Bu hipotezlerden en yaygın olanı Wilson'ın Biyofili Hipotezidir. Biyofili, genetik temelli olarak yaşam ile bağlantı kurmak ve yaşamı sürdürmek amacıyla ortaya çıkan insan ihtiyaçları ve eğilimleridir. Literatürde bireylerin mevsimsel değişiklikler, su, bitki, hayvan, hayvan sesleri ve hareketleri gibi doğal uyaranlara yakın olma isteğinin doğuştan var olan bir özellik vurgulanmakta (Kahn 1997), biyofili hipotezi, insanlar ile doğadaki diğer canlılar arasındaki içgüdüsel güçlü bir bağ olarak tanımlanmaktadır. Bu içgüdüsel bağ ne kadar kuvvetli olursa, insan hayvan etkileşimi de o kadar faydalı sonuçlanmaktadır (Ballarini 2003). İnsan ve doğadaki diğer canlılar arasındaki bu güçlü bağın terapötik etkilerinin olduğu vurgulanmaktadır.

HDU'nun dayandırıldığı teorilerden bir diğeri Öğrenme Teorisidir. Öğrenme teorisinde uyaran ve uyarana verilen tepkinin varlığından söz edilmektedir. Uyarana verilen tepkiden tatmin edici sonuçlar alındığında uyaran ve tepki ilişkisinin pekiştirilerek bireyde doyum sağladığı belirtilmektedir. Bu doyum, tepkinin/davranışın tekrarlanma sıklığını artırmaktadır. Hoşnutsuzluk ise bireyin denemeyanılma yoluyla yeni çözüm yollarını keşfetmesini sağlar. Bu teori hayvan destekli uygulamalar sürecinde stres ve anksiyetenin azalmasını açıklayan bir teoridir. Hayvan destekli uygulamalarda bireylerin ilgisi hoşnutsuz oldukları hastalık ve semptomlarından, hoşnutluk sağladıkları hayvan etkileşimine doğru çekilmektedir (Braastad \& Berget 2010). İnsan ve hayvan etkileşiminden sağlanan doyum ruhsal iyilik halinin korunması ve geliştirilmesinde katkı sunmaktadır.

Uygulamayı açıklayan bir diğer teori Psikoanalitik Teoridir. Bu teoride, bireylerin açıklamakta zorlandığı duygu, düşünce ve çatışmalarını, gerçek veya hayali nesne ya da figürlere yansıttıkları belirtilmektedir. Hayvan destekli uygulama sürecinde de bireylerin, dışa yansıtamadıkları duygu ve düşüncelerini gerçek veya hayali hayvanlara yansıtarak ifade edebilmeleri sağlanmaktadır. Ayrıca, psikoanalitik teoride belirtilen gelişimin psikososyal aşamalarına bireyin uyum sağlamasında hayvan destekli uygulamaların kolaylaştırıcı faktör olacağı vurgulanmaktadır (Bruneau \& Johnson 2011).

HDU'nun temel aldığı bir başka kuram, John Bowlby ve Mary Ainsworth'un geliştirdiği Bağlanma Kuramıdır. Bu kurama göre bireyler arasındaki güçlü bağ "bağlanma" olarak tanımlanmış, kendini güçsüz hisseden, yalnız ya da hasta bireylerin de kendileri için önemli olan başka bir canlı ya da nesne ile güçlü duygusal bağlar kurma eğilimi olduğu belirtilmiştir (Fine 2006'dan akt. İncazlı et al. 2016). HDU, evcil hayvan sahibi olmayan bireylere, destekleyici, güvenilir bir durumda hayvanlarla etkileşim kurma şansı verir (Officical Journal of ANA 2008). Uygulama kapsamında kullanılan hayvan özellikle de çocuklarda güven ve sakinlik veren bağlanma figürü olarak işlevsellik göstermektedir (Kruger \& Serpell 2010). 
HDU’yu açılayan bir diğer kavram, Yeşil Terapi kavramıdır. Yeşil terapi, terapötik bahçecilik, hayvan destekli terapi, tarım, egzersiz gibi birçok uygulamayı içeren karmaşık bir yöntemdir (Berget \& Ihlebaek 2011). Doğal alanların bireyler ve hastalar üzerinde ağrı ve semptomları, ilaç kullanımını, gerginlik ve stresi azaltıcı etkilerinin olduğu vurgulanmaktadır (Yılmaz 2017). Yeşil terapiye göre insanlar günlük stresten bitkiler ve hayvanlar ile meşgul olarak kurtulmaya çalışmakta ve böylece yaşam kaliteleri iyileşmektedir (Berget \& Ihlebaek 2011). Hayvan destekli uygulamalarda terapi hayvanı doğal ortamları simgeleyerek insan ve hayvan etkileşimi ile bireylere terapötik etkiler sağlayabilmektedir.

Bilişsel Davranışcı Kuramda HDU ile ilişkilendirilmektedir. Bu kuram, bireylerin davranışları ve bilişsel süreçleri arasında sürekli bir ilişki olduğunu ortaya koymaktadır (Türkiye Psikiyatri Derneği 2019). HDU'nın sonrasında bireyin özyeterliliği ve benlik saygısındaki değişimler, davranışlarında da olumlu değiş̧imlere neden olmaktadır. Bireyde meydana gelen değişimler hayvanla etkileşiminin sonucunda öğrenme ve taklit yoluyla gerçekleşmektedir. (Kruger \& Serpell 2010). Dolayısıyla, bireylerde bilişsel ve davranışsal olarak meydana gelen değişimler bu kuramla desteklenmektedir. (Berget \& Ihlebaek 2011).

\section{Hayvan Destekli Uygulamaların Etki Mekanizması}

HDU'ya ilişkin yapılan araştırmalarda, HDU'nun temel prensibi, insan ve hayvan etkileşiminin sonucunda, bireydeki ruhsal, fiziksel ve sosyal değişimlere bağlı olarak psikosomatik değişimlerin ortaya çıktığı düşüncesine dayandırılmaktadır. Bu etkiler birbiriyle ilişkili olan psikolojik uyarı, fiziksel, oyun, affektif-duygusal ve psikosomatik mekanizmalarla açıklanmaktadır.

Psikolojik Uyarı Mekanizmasına göre, bir hayvanın bakımı ile ilgilenmenin, bireyin kendi problemlerinden uzaklaşmasını sağladığı (Ballarini 2003) stres ve anksiyete düzeyini azalttığı (Cevizci et al. 2012; West 2018), yaşam kalitesini, sağlık algısını ve ruhsal iyilik halini artırdığı (McCullough et al. 2017) belirtilmektedir.

Fiziksel ve Oyun Mekanizmasına göre, bireyin hayvan ile vakit geçirmesi, oyun oynaması bireyin fiziksel aktivitesini artırmaktadır. Fiziksel ve oyun mekanizmaları insan sağlığı için önemlidir ve bireyin iyileşme potansiyelini artırır (Ballarini 2003). HDU kapsamında yer alan at binme, yunuslarla yüzme, köpeklerle gezinti ve kedilerle oyun oynama gibi aktiviteler fiziksel ve oyun mekanizmasının işleyiş̧ini açıklamaktadır (Ballarini 2003; Berget \& Ihlebaek 2011).

Affektif-Duygusal Mekanizmaya göre, insan-hayvan arasındaki güven verici, sakinleştirici ve olumlu ilişki bağlanmayı sağlar. İnsan-hayvan arasındaki etkileşim ne kadar fazla ise bu mekanizma o kadar etkilidir (Ballarini 2003). İnsan-hayvan etkileşimi sonucunda, stres hormonlarının salınımı azalarak, kan basıncında, nabız ve solunum hızında düşmeye neden olur (McCullough et al. 2017). HDU, bireyin gevşemesini sağlayan biyokimyasal reaksiyonları aktif hale getirir (West 2018).

Psikosomatik mekanizmalar ise hayvan destekli uygulamalarda açılanan psikolojik uyarı, fiziksel, oyun ve affektif-duygusal mekanizmaların tamamını kapsamaktadır. İnsan hayvan etkileşiminin bireyler üzerinde psikolojik, fiziksel (McCullough et al. 2017), duygusal ve sosyal açıdan bütüncül bir yarar sağladığı vurgulanmaktadır. Günümüzde hayvan destekli uygulamaların psikosomatik yakınmaların tedavisinde etkili bir yöntem olarak kullanılabileceğine yönelik çalışma sonuçları mevcuttur (Elmac1 \& Cevizci 2015; McCullough et al. 2017; West 2018).

\section{Hayvan Destekli Uygulamaların Kullanım Alanları}

Bireylerin sağlığını koruma ve geliştirmede HDU'ların farklı birçok kullanım alanı vardır. Kullanım amaçlarına göre kullanım alanları da farklılık göstermektedir. HDU'lar akademik başarısı düşük, okula uyum problemi yaşayan, özgüveni düşük, sosyalleşme yönü zayıf ya da gelişmemiş olan çocuklarda görülen, davranış bozukluklarının tedavisinde sıklıkla kullanılmaktadır (O’haire et al. 2014). Ek olarak, saldırgan davranışların azaltılması amacıyla hapishane, ıslahevi, ruh sağlığı hastaneleri gibi farklı kurumlarda (Ballarini 2003); psikiyatrik bozukların tedavi ve bakımı kapsamında hafif veya orta dereceli otizmli bireylerde (Elmac1 \& Cevizci 2015), depresyon, anksiyete- stres belirtilerin 
azaltılması ya da önlenmesinde (West 2018), çocukluk, ergenlik ve yaşl1lık gibi gelişim dönemlerine bağlı görülen sorunlarda fiziksel ve bilişsel değişikliklere uyum sağlanması için HDU'lar kullanılabilir (Cowel 2017). Ayrıca immun sistemi güçlendirmek (Charnetski et al. 2004), hastalıkların iyileşme dönemini olumlu yönde etkilemek, arteryel hipertansiyon, kardiyopatiler (Ballarini 2003), kronik kassinir sistemi hastalıkların tedavi ve bakımını sürdürmede, farklı motor bozuklukların tedavisi ve rehabilitasyonunu (Elmacı \& Cevizci 2015) sağlamada tıbbi müdahalelere ek olarak HDU'lar kullanılmaktadır.

\section{Hayvan Destekli Uygulamaların Bir Müdahale Yöntemi Olarak Kullanılması}

HDU, bireyleri sosyal, fiziksel, zihinsel, duygusal ve sosyal yönleriyle desteklemek ve geliştirmek için tasarlanan ve sağlı profesyonelleri (hekim, hemşire, psikolog gibi) tarafından uygulanan müdahale programlarından oluşmaktadır. Hemşirelerin de uygulayabileceği HDU programları hastane, huzurevi, bakım evlerinde ya da ev ziyaretleri yoluyla uygulanabilmektedir (Official Journal of ANA 2008). HDU programlarını uygulayan hemşireler müdahale ekibi içerisinde yer alabilmekte (Edwards \& Beck 2002) veya tek başlarına (Cowel 2017) bu uygulamayı yapabilmektedir. Hemşireler Hemşirelik Girişimleri Sınıflandırması'nda (NIC) yer alan hayvan destekli uygulama müdahaleleri kapsamında müdahalede bulunurlar. Bu müdahaleler arasında, bireyin hayvan ile etkileşime geçmesini destekleme, bireyin duygularını ifade etmesini sağlama, etkileşim için güvenli çevre oluşturma gibi girişimler yer almaktadır (NIC 2004).

\section{Hayvan Destekli Uygulamaların Sağladığı Yararlar}

HDU'nun bireyde psikolojik, duygusal, sosyal ve fiziksel birçok yarar sağladığ çalışmalarda vurgulanmaktadır. HDU'ya ilişkin yapılan çalışmalarda, hayvanların varlığının, birey duygu ifadesini, iletişimi ve kendine bakımı geliştirdiği (Elmacı \& Cevizci 2015), immun sistemi güçlendirdiği (Charnetski et al. 2004), kardiyovasküler sistemi düzenlediği (McCullough et al. 2017), ameliyat sonrası ağrı kesicilere duyulan ihtiyacı azalttı̆̆ 2016), anksiyete ve stres düzeylerini azalttığı (McCullough et al. 2017; West 2018), sağlık algısını iyileştirdiği (McCullough et al. 2017), bireyin egzersiz yapma oranını artırdığı (Cevizci et al. 2012), özgüveni ve çocukların okula devam isteğini artırdığı (O'haire et al. 2014) belirtilmektedir. HDU’lar, anksiyete (McCullough et al. 2017), depresyon, stres (McCullough et al. 2017; West 2018), travma sonrası stres bozuklukları, yalnızlık duygusu ile baş etme gibi birçok psikiyatrik bozukluğun tedavisinde de destekleyici tedavi olarak kullanılmaktadır (McCullough et al. 2017; Pamuk 2015). HDU'nun psikiyatri, pediatri, geriatri gibi psikiyatrik rehabilitasyonun ve hemşirelik bakımının ön planda olduğu birçok alanda özellikle de yaşlılar, engelliler (Elmacı \& Cevizci 2015), çocuklar (O’haire et al. 2014; Cevizci et al. 2015; İ́chitani \& Cunha 2016; McCullough et al. 2017) gibi incinebilir grupların tedavi ve rehabilitasyonunda kullanımına sık rastlanmaktadır.

\section{Sonuç ve Öneriler}

Geçmişten günümüze, ruh sağlığının korunması ve geliştirilmesinde, insan ve hayvanlar arasındaki etkileşiminin ve oluşan bağın olumlu etkisi yadsınamaz bir gerçektir. Son yıllarda yapılan çalışmalarda hayvan destekli uygulamaların birçok grup ve farklı hastalıkların tedavisinde kullanıldığı ancak ülkemizde bu konuda yapılan çalışmaların sınırlı olduğu tespit edilmiştir.

Birey ve toplumun ruh sağlığının korunması ve geliştirilmesi öncelikli hedeflerimiz arasındadır. HDU bireylerin sağlık durumunun geliştirilmesine, yaşam kalitesinin artırılmasına ve ruh sağlığının korunması ve iyileştirilmesinde diğer tedavilere ek olarak kullanılabilecek destek tedavi seçeneğidir. Koruyucu ruh sağlığı ve klinik psikiyatrik bakım uygulamalarında sağlık profesyonelleri tarafından uygulanabilir bir müdahaledir.

Bu bağlamda, ülkemizde de hayvan destekli uygulamalara ilişkin uygulama protokollerinin belirlendiği programların geliştirilmesi, hayvan destekli uygulamaların etki mekanizmasına uygun olarak belirlenecek farklı gruplarla yapılan çalışmalarla hayvan destekli uygulamaların etkililiğinin değer- 
lendirilmesi, farklı çalışma alanlarında kullanımının artırılması ve hayvan destekli uygulamaların yararlılığının çalışma sonuçları ile desteklenmesi önerilmektedir.

\section{Yazar Notu:}

Bu çalışma, Antalya 20-23.11.2018 tarihleri arasında düzenlenen V. Uluslararası IX. Ulusal Psikiyatri Hemşireliği Kongresi'nde sözel bildiri olarak sunulmuştur. Ayrıca Psikiyatri Hemşireliği Dergisi'nin $V$. Uluslararası IX. Ulusal Psikiyatri Hemşireliği Kongresi'nde sunulan çalışmaların özetlerinin yayınlandığı ek sayıda, özet olarak yayınlanmıştır. 


\section{KAYNAKÇA}

Ballarini G. (2003). “Pet Therapy Animals in Human Therapy. Conference Report”. ActaBioMedica 74 (2003) 97-100.

Berget B. \& Ihlebaek C. (2011). “Animal-Assisted Interventions; Effects on Human Mental Health - a Theoretical Framework”. Psychiatric Disorders - Worldwide Advances (2011) 121-138. doi: 10.5772/27318

Braastad B. O. \& Berget B. (2018). "Theoretical Frameworks for Animal-Assisted Interventions”. Department of Animaland Aquacultural Sciences (2018) 1-16.

Bruneau L. \& Johnson A. (2011). "Fidoand Freud Meet: Integrating Animal-Assisted Interventions with Counseling Theory”. American Counseling Association Conference 14 (2011) 1-14.

Cevizci S., Babaoğlu Ü. T., Erginöz E. \& Sever H. (2012). “İstanbul'un Beşiktaş İlçesi’nde Özel Bir Firmada Beyaz Yakalı Çalışanlarda Hayvan Beslemenin Psikolojik Stres, Düzenli Fiziksel Egzersiz ve Sigara İçme ile İlişkisi”. Nobel Med. 8/3 (2012) 52-59.

Charnetski J. C. \& Riggers S. (2004). "Effects of Petting a Dog on Immune System Function”. Psychological Reports 95/3 (2004) 1087-1091.

Cowel D. R. (2017). A Clinical Practice Change Initiative to Incorporate Animal Assisted Therapy in Advanced Practice Registered Nurses' Clinical Practice for Children and Adolescents. Doctoral Projects. University of Southern Mississippi, Hattiesburg 2017.

Edwards N. E. \& Beck A. M. (2002). “Animal-Assisted Therapy and Nutrition in Alzheimer's Disease”. Western Journal of Nursing Research 24/6 (2002) 697-712.

Elmacı D. T. \& Cevizci S. (2015). "Dog-Assisted Therapies and Activities in Rehabilitation of Children with Cerebral Palsy and Physical and Mental Disabilities". International Journal of Environmental Research and Public Health 12 (2015) 5046-5060. doi:10.3390/ijerph120505046

İchitani T. \& Cunha C. (2016). "Effects of Animal-Assisted Activity on Self Reported Feelings of Pain in Hospitalized Children and Adolescents". Psicologia: Reflexao Critica 29/43 (2016) 1-10.

İncazlı S. B., Özer S. \& Yıldırım Y. (2016). "Rehabilitasyon Hemşireliğinde Hayvan Destekli Uygulamalar". Ballkesir Sağllk Bilimleri Dergisi 5/2 (2016) 88-93.

Kahn P. H. (1997). "Developmental Psychology and the Biophilia Hypothesis: Children's Affiliation with Nature”. Develop Mental Review 17/1 (1997) 1-61.

Kruger K. A. \& Serpell J. A. (2010). "Animal-Assisted Interventions in Mental Health: Definitions and Theoretical Foundations". Handbook on Animal-Assisted Therapy (2010) 33-48.

McCullough A., Ruehrdanz A., Jenkins M. A., Gilmer M. J., Olson J., Pawar A., ... \& O’Haire E. (2018). "Measuring the Effects of an Animal Assisted Intervention for Pediatric Oncology Patients and Their Parents: A Multisite Randomized Controlled Trial”. Journal of Pediatric Oncology Nursing 35/3 (2018) 159-177.

Nursing Interventions Classification (NIC). (2004). Kaynak: http://www.seapaonline.org/uploads/ documentacion/Metodolog\%C3\%ADa\%20Enfe rmera/labeldefinitions-NIC.pdf. Erişim Tarihi: 09 Ocak 2019.

O’Haire M. E., McKenzie S. J., McCune S. \& Slaughter V. (2014). "Effects of Class Room Animal-Assisted Activities on Social Functioning in Children with Autism Spectrum Disorder". The Journal of Alternative and Complementary Medicine 20/3 (2014) 162-168. doi: 10.1089/acm.2013.0165

Officical Journal of ANA (2008). "Unleash the Healing Power of Pet Therapy". Officical Journal of ANA 3/5 (2008). Kaynak: https://www.americannursetoday.com/unleash-the-healing-power-of-pet-therapy/. Erişim Tarihi: 05 Aralık 2018.

Pamuk D. (2015). "Yaşlı Bireylerin Yaşamında Evcil Hayvanların Rolü". MJH V/2 (2015) 297-306. Doi:10.13114/MJH.2015214573

Türkiye Psikiyatri Derneği (2019). Bilişsel Davranışçı Psikoterapi. Kaynak: http://www.psikiyatri.org.tr/halkayonelik/36/bilissel-davranisci-psikoterapi. Erişim Tarihi: 02 Temmuz 2019.

West B. (2018). Effects of Animal-Assisted Therapy on Self-Perceived and Physiological Stress. Master's Thesis. Webster Vienna Private University, Vienna 2018.

Yılmaz E. (2017). Hastanelerde Terapi Bahçelerinin İyi Olma Haline Etkilerinin Araştırlması. Yayımlanmamış Yüksek Lisans Tezi. Fatih Sultan Mehmet Vakıf Üniversitesi, İstanbul 2017. 